\title{
Consensus conference: activity of sarcoidosis
}

\author{
Third WASOG meeting, Los Angeles, USA, September 8-11, 1993.*
}

The term "activity" is widely applied in research and clinical practice when dealing with sarcoidosis. There are two major problems, however, associated with its use. Firstly, the term is not precisely defined; there is no general consensus on its meaning. Secondly, the tests used to assess activity include a battery of new markers for most of which the clinical relevance is not proven, and the validation against a "gold standard" is lacking.

\section{Definition of activity}

Activity means that something is still acting or working, is causing motion or change, is still evolving, or has not come to rest. In sarcoidosis, the term activity implies that the disease is undergoing clinical, roentgenographical or physiological change as a consequence of the persistence of the inciting event, which of course is still unknown. In the light of recent advances in the understanding of the pathogenesis of sarcoidosis [1], it is immediately clear that the three different phases in the evolution of the disease may be considered separately, and that different markers can be associated with the different phases. Thus, "active" sarcoidosis may imply that: 1) the T-lymphocyte/macrophage inflammation is still ongoing; 2) the process of granuloma formation is still evolving; and 3) there is still progression to fibrosis occurring.

The extent of active disease needs to be distinguished from the total extent of disease (i.e. number of organs involved; number of granulomas within affected organs). In addition, activity should not be mistaken for: 1) the outcome of disease (e.g. Löfgren's syndrome, clinically active, has the best prognosis); and 2) the necessity to start corticosteroid treatment (active acute disease may spontaneously resolve in a high percentage of patients).

Taking the above into account, and in the knowledge that various manifestations of disease activity are possible, the following definitions for active and inactive sarcoidosis are proposed. In active disease, patients may present with clinical signs of activity, and/or with biological/immunological markers of either active alveolitis, and/or active granuloma formation, and/or active progression to fibrosis. In inactive disease, the clinical signs show regression or remain stable, and biological/ immunological markers are within the normal range.
Ideally, when referring to a patient with sarcoidosis and active disease, the sign(s) or marker(s) indicating disease activity should be stated.

\section{Markers of activity}

A test or marker of a disease like sarcoidosis may serve for different purposes: 1) as a diagnostic test it predicts the presence or absence of the disease; 2) as a marker of activity it predicts the presence or absence of active disease; and 3) as a prognostic factor it predicts disease progression and long-term outcome.

For tests of inflammation, granuloma formation or fibrosis to be accepted as markers of active disease, they must be associated with a changing clinical, roentgenographical or physiological condition that causes or can cause symptoms or disability. An ideal test to measure activity should be simple, easily repeatable, reproducible, and should indicate whether the pathological or immunological process is still ongoing or quiescent. Some markers of activity may have the additional benefit of being prognostic factors indicating disease outcome. Unfortunately, there is no single test available at present which at the time of diagnosis would accurately predict the likelihood of disease progression.

\section{Individual activity markers}

During the last $20 \mathrm{yrs}$, a wide range of clinical and biological/immunological tests have been claimed to have a potential as activity markers [1-5]. For practical purposes, they can be categorized into clinical indices including imaging techniques, serum markers, and bronchoalveolar lavage (BAL) parameters (table 1).

\section{Clinical indices (including radiology and isotope stud- ies)}

Acute disease, with fever, erythema nodosum, and/or polyarthralgia, is clearly clinically active, and, nevertheless, carries the best prognosis; $>80 \%$ of patients will spontaneously improve. Splenomegaly and skin lesions other than erythema nodosum are considered to be manifestations of chronic and severe disease.

*Prepared by a panel of the World Association of Sarcoidosis and Other Granulomatous Disorders (WASOG). Panel members: U. Costabel (Chairman), R. du Bois, A. Eklund, D.G. James, W. Jones-Williams, H. Klech, S. Nagai, L. Newman, A.H. Niden, M. Rossman, C. Saltini, G. Semenzato, A. Teirstein. Correspondence: U. Costabel, Dept of Pneumology/Allergy, Ruhrlandklinik, Tüschener Weg 40, D-45239 Essen, Germany. 
Table 1. - Markers of activity investigated in sarcoidosis

\begin{tabular}{lcc}
\hline Clinical & Serum & BAL \\
\hline Fever & Macrophage/granuloma associated & Lymphocytes \\
Uveitis & Calcitrol/hypercalcaemia & CD4/CD8 ratio \\
Erythema nodosum & ACE & Collagenase \\
Lupus pernio & Lysozyme & PCP-III \\
Macopapular rash & Carboxypeptidase & Hyaluronan \\
Changing scars & Thermolysin-like metallopeptidase & Fibronectin \\
Polyarthralgia & Neopterin & Vitronectin \\
Splenomegaly & Lymphocyte associated & \\
Progressive symptoms & $\beta_{2}$-microglobulin & \\
(dyspnoea, cough) & Soluble interleukin-2 receptors & \\
Deteriorating chest & Adenosine deaminase & \\
radiograph & Interferon-gamma & \\
Worsening lung function & Immune complexes & \\
Positive 67Ga scan & Hypergammaglobulinaemia & \\
& Extracellular matrix associated & \\
& PCP-III & \\
\hline
\end{tabular}

BAL: bronchoalveolar lavage; ACE: angiotension converting enzyme; PCP-III: procollagen III peptide.

Traditional indicators of activity are worsening respiratory symptoms and deterioration of lung function or of chest radiograph. Stage I (bihilar lymphadenopathy (BHL) alone) has a spontaneous remission rate of $60-80 \%$, stage II (BHL and parenchymal infiltrates) of about $60 \%$, and Stage III (parenchymal infiltrates only) of less than $30 \%$.

Abnormal lung function tests, particularly vital capacity, forced expiratory volume in one second $\left(\mathrm{FEV}_{1}\right)$, and diffusing capacity of the lungs for carbon monoxide (DLCO), are traditionally used as indication for treatment. Baseline function tests are not related to the probability of disease progression. Lung function studies cannot distinguish between fresh, reversible granulomatous lesions and irreversible fibrotic changes. There is only a loose correlation between lung function tests and chest radiography.

Computed tomography (CT), particularly in its high resolution form (HRCT), is superior to the radiograph in demonstrating early fibrosis and distortion of the lung parenchyma. Ground-glass opacities on HRCT may represent areas of active alveolitis, as assessed by $67 \mathrm{Ga}$ scanning. Whether HRCT is also useful as a predictor of disease progression remains to be elucidated [6].

Gallium-67 scanning is based on the uptake of $67 \mathrm{Ga}$ by macrophages and granuloma cells. A positive scan reflects the macrophage inflammation and the presence of granulomata. $67 \mathrm{Ga}$ scans have a high sensitivity $(>90 \%)$ but a poor specificity $(30-60 \%)$ for detecting clinically active disease $[7,8]$. Most studies indicate that $67 \mathrm{Ga}$ scanning is not helpful for treatment decisions [9-11]. Considering also the diasadvantages of costs, radiation exposure and problems with standardization, $67 \mathrm{Ga}$ scan cannot be recommended for routine use in staging of sarcoidosis.

99mTc-diethylenetriamine penta-acetate (DTPA) is an isotope used to assess the permeability of the terminal respiratory epithelium to solutes. DTPA clearance is increased in some patients with sarcoidosis, as in other inflammatory lung diseases. Whether DTPA clearance can identify those patients who are likely to remain stable or deteriorate, as suggested by a recent study [12], has to be further evaluated.

\section{Serum markers}

Serum angiotensin converting enzyme (SACE) is probably the most widely-used laboratory test in sarcoidosis, with an estimated global sensitivity of $57 \%$ and a specificity of $90 \%$ [13]. SACE values are higher in clinically active than in inactive disease, and correlate with the extent of disease [7-9, 14]. SACE is often normal during the first months of acute disease with erythema nodosum [15]. ACE is produced by epithelioid cells of the granulomas and alveolar macrophages. The serum levels probably reflect the total-body granuloma burden and not just the degree of lung involvement. A lack of change in SACE, despite improvement in lung function, and the lack of correlation with BAL lymphocytes or Tcell subsets, could simply reflect a difference in disease activity in various organs. There is no correlation between the initial SACE level and the response to treatment or the final prognosis $[9,16]$. The initial values are not different between patients who deteriorate and those who improve [17-19]. Thus, an elevated SACE level alone is no indication to start corticosteroid therapy. Once treatment has been initiated for other reasons, however, SACE can be used to monitor the effect of treatment. It falls to normal following steroid therapy, and a rising level may herald a relapse $[9,20]$.

Hypercalcaemia has long been recognized as an important complication of sarcoidosis, the prevalence ranging between $5-10 \%$. It is caused by an overproduction of calcitriol, the active form of vitamin $\mathrm{D}_{3}$, most probably in granulomas by activated macrophages [21]. Hypercalcaemia may, thus, be considered as a marker of the granuloma activity, but with a low sensitivity.

Several other serum markers of disease activity have 
been proposed in sarcoidosis, but none has been established as a clinical test in routine examination $[4,5]$. Serum lysozyme, a product of macrophages and epithelioid cells in granuloma, offers no additional advantage to SACE, and is even less specific. Other macrophagederived enzymes reported to be elevated in serum of sarcoidosis patients include carboxypeptidase $\mathrm{N}$, and thermolysin-like metalloendopeptidase (TME). None has proved to be useful clinically [3-5]. Also beta - -microglobulin and adenosine deaminase measurements, indicating activation of lymphocytes, have never achieved a role in clinical practice, owing to low sensitivity and low specificity [3-5].

More recently, cytokines and lymphocyte-derived receptors, such as interferon-gamma and soluble interleukin-2 receptors, as well as the macrophage-derived product neopterin, have been assayed as activity markers [22-26]. Whether these tests are superior to other markers is at present unknown.

Extracellular matrix associated products are potential markers of lung fibroblast activity, and may reflect the early fibrosing activity of interstitial lung diseases, including sarcoidosis. In one study [27] serum procollagenIII peptide (PCP-III) levels did not predict prognosis but in another study [28] the levels were found to be significantly higher in patients with progressive disease although there was considerable overlap in individual values between the stable and progressive groups, however. Confirmatory studies, in either direction, are needed before routine measurements of serum PCP-III can be recommended for the assessment of sarcoidosis. This is also true for other extracellular matrix products, including hyaluronan, fibronectin, and vitronectin [5].

\section{BAL parameters}

Initially, it had been hoped that BAL parameters, particularly abnormalities in the cell populations, would prove more useful in the assessment of activity and prognosis than peripheral blood tests. At present the consensus reached is that the intensity of the alveolitis, as assessed by either BAL lymphocyte counts or CD4/CD8 ratios, does not predict outcome in an individual patient, and thus should not be used as sole criterion for treatment decisions [9, 10, 16, 29-33]. The concept [34] that patients with sarcoidosis should be grouped into those with high intensity ( $>28 \%$ T-lymphocytes and a positive $67 \mathrm{Ga}$ scan) and low intensity alveolitis ( $\leq 28 \%$ T-lymphocytes and/or a negative $67 \mathrm{Ga}$ scan) is no longer valid. Of special concern is the frequent misuse of the term high intensity by using only one criterion, namely $>28 \%$ $\mathrm{T}$-lymphocytes, and omitting the $67 \mathrm{Ga}$ scan in this classification. Such disease classification is strongly discouraged.

An important consideration is the influence of disease duration on the BAL composition in sarcoidosis. Patients with early acute disease (erythema nodosum, acute uveitis) almost invariably have high BAL lymphocyte counts and CD4/CD8 ratios [35]. Any series which includes a high proportion of patients with such presentation will not find these BAL parameters to be predictive of poor prognosis.

Most of the aforementioned serum markers have also been tested in BAL fluid as activity markers and found to be of disputable clinical value [36]. Another soluble factor measured in BAL is collagenase activity. This enzyme was found to be predictive of short-term outcome [37], but long-term follow-up studies and confirmation by other groups are needed before clinical recommendations can be given.

\section{Conclusions}

For the clinical management of patients with sarcoidosis, at present the routine tests to stage the activity of disease can be limited to the following: 1) clinical investigation; 2) chest radiography; and 3) lung function testing.

Optionally, in a select clinical setting, the following may also be useful: 1) serum ACE; 2) 67Ga scan; 3) (high resolution) CT; and 4) BAL cell populations and CD4/CD8 ratio.

All other aforementioned markers have, so far, no established clinical value and in order to validate their use should be further investigated in large, prospective studies with predetermined serial measurements. Patients with acute presentation and Stage I disease should be evaluated separately, since the majority will spontaneously recover despite showing a high initial inflammatory acti-vity. The gold standard against which new activity tests should be validated is conventional, and includes clinical, radiological and physiological assessment.

\section{References}

1. Semenzato G, Agostini C. Immunology of sarcoidosis. In: Schwarz MI, King TE, eds. Interstitial lung disease. 2nd edn. St. Louis, Mosby Year Book, 1993: pp. 127-158.

2. Chrétien J, Venet A, Israel-Biet D, Clavel F, Sandron D. Summary statement on disease activity assessment. Ann NY Acad Sci 1986; 465: 479-481.

3. Chrétien J. Assessment of sarcoid activity. State of the art. In: Grassi $\mathrm{C}$, et al. eds. Sarcoidosis and other granulomatous disorders. Amsterdam, Elsevier, 1988; pp. 525-539.

4. Baudouin SV, du Bois RM. Disease activity in sarcoidosis. In: James DG, ed. Sarcoidosis and Other Granulomatous Disorders. New York, Marcel Dekker, 1994; (in press).

5. Costabel U. Biochemistry. In: James DG, ed. Sarcoidosis and Other Granulomatous Disorders. New York, Marcel Dekker, 1994; (in press).

6. Hansell DM. High resolution computed tomography in sarcoidosis and extrinsic allergic alveolitis: imaging insights. Sarcoidosis 1992; 9: 21-28.

7. Gupta RG, Oparil S, Szidon JP. Clinical significance of serum angiotensin-converting enzyme levels in sarcoidosis. J Lab Clin Med 1979; 93: 940-949.

8. Klech H, Köhn H, Kummer F, Mostbeck A. Assessment of activity in sarcoidosis. Chest 1982; 82: 732-738.

9. Hollinger WM, Staton GW, Fajman WA, Gilman MJ, Pine RJ, Check IJ. Prediction of therapeutic response in 
steroid-treated pulmonary sarcoidosis. Am Rev Respir Dis 1985; 132: 65-69.

10. Turner-Warwick M, McAllister W, Lawrence R, Britten A, Haslam PL. Corticosteroid treatment in sarcoidosis: do serial lavage lymphoycte counts, serum ACE measurements and gallium-67 scans help management? Thorax 1986; 41: 903-913.

11. Niden AH, Mishkin FS, Salem F, Thomas AV, Kamdar V. Prognostic significance of gallium lung scans in sarcoidosis. Ann NY Acad Sci 1986; 465: 435-443.

12. Chinet T, Dusser D, Labrune S, Collignon MA, Chrétien J, Huchon GJ. Lung function declines in patients with pulmonary sarcoidosis and increased respiratory epithelial permeability to 99mTcDTPA. Am Rev Respir Dis 1990; 141: 445-449.

13. Studdy PR, James DG. The specificity and sensitivity of serum ACE in sarcoidosis and other diseases. In: Chrétien J, et al. eds. Sarcoidosis. Paris, Pergamon, 1983: pp. 332-344.

14. Muthuswamy PP, Lopez-Majano V, Ranginwala M, Trainor WD. SACE activity as an indicator of total body granuloma load and prognosis in sarcoidosis. In: Grassi C, et al. eds. Sarcoidosis and Other Granulomatous Disorders. Amsterdam, Elsevier, 1988; pp. 603-604.

15. Grönhagen-Riska C, Selroos O, Wager G, Fyhrquist F. Angiotensin-converting enzyme. II. Serum activity in early and newly diagnosed sarcoidosis. Scand J Respir Dis 1979; 60: 94-101.

16. Baughman RP, Fernandez M, Bosken CH, Mantil J, Hurtubise P. Comparison of gallium-67 scanning, bronchoalveolar lavage, and serum ACE levels in pulmonary sarcoidosis. Am Rev Respir Dis 1984; 129: 676-681.

17. Choudat D, Stanislas-Leguern GM, Mordelet-Dambrine MS, Chrétien J, Huchon GJ. Serum activity of ACE and pulmonary radiography as prognosis criteria in sarcoidosis. Eur J Respir Dis 1983; 64: 355-359.

18. Rust M, Bergmann L, Kuhn T, et al. Prognosis value of chest radiograph, serum ACE and T-helper cell count in blood and in BAL of patients with sarcoidosis Respiration 1985; 48: 231-236.

19. Harf R, Biot N, Perrin-Fayolle M, et al. Prognostic value of ACE, lysozyme and pulmonary lymphocytosis in sarcoidosis. In: Grassi C, et al. eds. Sarcoidosis and other granulomatous disorders. Amsterdam, Elsevier, 1988: pp. 595-597.

20. Römer FK, Jacobsen F. The influence of prednisone on ACE activity in patients with and without sarcoidosis. Scand J Clin Lab Invest 1982; 43: 377-382.

21. Adams JS, Sharma OP, Gacad MA, Singer FR. Metabolism of 25-hydroxyvitamin $\mathrm{D}_{3}$ by cultured pulmonary alveolar macrophages in sarcoidosis. J Clin Invest 1983; 72 1856-1860.

22. Prior C, Haslam PL. Increased levels of serum interferon-gamma in pulmonary sarcoidosis and relationship with response to corticosteroid therapy. Am Rev Respir Dis 1991; 143: 53-60.

23. Lawrence EC, Brousseau KP, Berger MB, Kurman CC, Marcon L, Nelson DL. Elevated concentrations of soluble interleukin-2 receptors in serum samples and BAL fluids in active sarcoidosis. Am Rev Respir Dis 1988; 137: 759-764.

24. Keicho N, Kitamura K, Takaku F, Yotsumoto H. Serum concentration of soluble interleukin-2 receptor as a sensitive parameter of disease activity in sarcoidosis. Chest 1990; 98: 1125-1129.

25. Müller-Quernheim J, Pfeifer S, Strausz J, Ferlinz F. Correlation of clinical and immunologic parameters of the inflammatory activity of pulmonary sarcoidosis. Am Rev Respir Dis 1991; 144: 1322-1329.

26. Eklund A, Blaschke E. Elevated serum neopterin levels in sarcoidosis. Lung 1986; 164: 325-323.

27. Luisetti M, Bulgheroni A, Bacchella, Pasturenzi L, Aprile C. Elevated serum procollagen III aminopeptide levels in sarcoidosis. Chest 1990; 98: 1414-1420.

28. Pohl WR, Thompson BA, Köhn H, et al. Serum procollagen III peptide levels in subjects with sarcoidosis. A 5 year follow-up study. Am Rev Respir Dis 1992; 145: 412-417.

29. Israel-Biet D, Venet A, Chrétien J. Persistent high alveolar lymphocytosis as a predictive criterion of chronic pulmonary sarcoidosis. Ann NY Acad Sci 1986; 465: 395-406.

30. Bjermer L, Rosenhall L, Angström T, Hällgren R. Predictive value of bronchoalveolar lavage cell analysis in sarcoidosis. Thorax 1988; 43: 284-288.

31. Verstraeten A, Demedts M, Verwilghen J, et al. Predictive value of bronchoalveolar lavage in pulmonary sarcoidosis. Chest 1990; 98: 560-567.

32. Laviolette M, La Forge J, Tennina S, Boulet LP. Prognostic value of bronchoalveolar lavage lymphocyte count in recently diagnosed sarcoidosis. Chest 1991; 100: 380-384.

33. Agostini C, Trentin L, Zambello R, et al. CD8 alveolitis in sarcoidosis: incidence, phenotypic characteristics, and clinical features. Am J Med 1993; (in press).

34. Keogh BA, Hunninghake GW, Line BR, Crystal RG. The alveolitis of sarcoidosis. Evaluation of natural history and alveolitis-dependent changes in lung function. Am Rev Respir Dis 1983; 128: 256-265.

35. Ward K, O'Connor C, Odlum C, Fitzgerald MX. Prognostic value of bronchoalveolar lavage in sarcoidosis: the critical influence of disease presentation. Thorax 1989; 44: 6-12.

36. Poulter LW, Rossi GA, Bjermer L, et al. The value of bronchoalveolar lavage in the diagnosis and prognosis of sarcoidosis. Eur Respir Rev 1992; 2: 75-82.

37. Ward K, O'Connor C, Odlum C, Power C, Fitzgerald GM. Pulmonary disease progression in sarcoid patients with and without bronchoalveolar lavage collagenase. Am Rev Respir Dis 1990; 142: 636-641. 